\title{
Oxygen and Everest.
}

\section{By Raymond Greene.}

$\mathrm{T}$ HE recent success of the British Himalayan Expedition in climbing, without the use of oxygen, ten of the greater Himalayan peaks, including Kamet (25,447 feet), the highest summit yet attained, has brought once more into prominence the question of the use of oxygen on Everest. It is a question on which both climbers and physiologists are divided. It is possible that an attempt to sum up the present position may be of use in future discussion.

The problem to be solved is whether or not oxygen can be regarded as a helpful factor in high climbing. One school of thought claims that, in the face of theoretical considerations and practical experience, it is impossible to deny its usefulness. The special difficulties of Everest are due chiefly not to terrain or climate but to want of oxygen. To supply this want can scarcely fail to reduce the difficulties of the ascent. Moreover, Prof. J. Barcroft has shown by direct experiment that, under laboratory conditions, it is possible to do by means of oxygen what is certainly impossible without it to climb at a rate of a thousand feet an hour, without previous acclimatisation, at a barometric pressure equal to that of the summit of Everest. Much practical experience points in the same direction. Of the ascent of the Rapiu La (21,000 feet), Prof. G. I. Finch wrote: "Colonel Strutt and Doctor Wakefield, unoxygenated, accompanied us on this little expedition, and oxygen at once proved its value, so easily did Bruce and I outpace them". Later, writing of May 22, 1922, he recorded that "There had been a considerable amount of stepcutting, but even so, oxygen had made a brief alpine ascent of what is otherwise a strenuous day's work". Of May 24 he wrote: "No longer did the porters regard oxygen as a foolish man's whim. One and all appreciated the advantages of what they naïvely chose to call 'English air '." As to its use in emergency, I will again quote Finch. He and Geoffrey Bruce had spent a miserable night at a height of 25,500 feet, about the height of Kamet. The weather was cold and windy but they decided to spend a second night at this camp. He wrote : " a dead, numbing cold was creeping up my limbs, a thing I had only once before felt. . . . Something had to be done. Like an inspiration came the thought of trying the effect of oxygen. . . . A few minutes later, after the first deep breath, I felt the tingling sensation of returning life and warmth to my limbs. We connected up the apparatus in such a way that we could breathe a small quantity of oxygen throughout the night. The result was marvellous. We slept well and warmly. Whenever the tube delivering the gas fell out of Bruce's mouth as he slept, I could see him stir uneasily in the uric, greenish light of the moon as it filtered through the canvas. Then, half unconsciously replacing the tube, he would fall once more into a peaceful slumber. There is little doubt that it was the use of oxygen which saved our lives during this second night in our high camp." On the next day, the two climbers climbed a further 1800 feet at an average speed of nine hundred feet an hour. An earlier party, using no oxygen, a stronger party from a mountaineering point of view, in better weather and after only one night in the high camp, covered roughly the same zone of altitude at a speed of only 330 feet an hour. It is on such data, derived from theoretical considerations, laboratory experiment, and practical experience, that the oxygen school bases its conclusions.

The no-oxygen school claims, on the other hand, that the conclusions are unsound because, both in the Barcroft steel chamber experiment and on Everest, the 'subjects' were either unacclimatised or only partially acclimatised. Acclimatisation appears to occur in three different ways. In the well-trained person, oxygen secretion by the lung epithelium increases the oxygen supply to the blood at a very early stage of an ascent. The existence of oxygen secretion is denied by some physiologists. In this battle of the giants I do not propose to take a part. It does not affect our main issue, because it does not occur to a sufficient extent to affect the question of whether or not oxygen should be carried on Everest. A great increase in the hæmoglobin percentage of the blood undoubtedly occurs, but this increase will not make possible the continuance of life at very great altitudes, unless supported by an actual increase in the pressure of oxygen in the lung alveoli. This increase is attained by deep breathing.

The first deep breathing of the ascending climber is caused by the effect of oxygen want, which increases the susceptibility of the respiratory centre to an increase in the carbon dioxide of the blood. The 'subject' responds to oxygen want by breathing more deeply. In so doing he washes carbon dioxide out of his blood and so lowers the acidity of the latter, and the tendency towards deep breathing. He may even show the periodic type of breathing known as ' Cheyne-Stokes breathing'. The most important element of acclimatisation is the overcoming of this 'alkalosis', and the breaking of the vicious circle. This compensation is brought about by an increased excretion of alkali by the kidneys. Thus a compensation towards acidosis is produced and permanent deep breathing with increased oxygen tension follows. Now the exponents of oxygen point out that although it is obvious that the supply of oxygen to an unacclimatised person would increase his working capacity, the acclimatised person would be unaffected. His deep breathing keeps his oxygen tension as high as he wants it.

The no-oxygen school can also quote from practical experience, for the evidence of the 1924 Everest Expedition was less favourable than that of the 1922 Expedition. There is, it is true, a record of 
a quick oxygen-assisted climb between Camps III. and IV. by Mallory and Irvine, and there is a note by Mallory, written from Camp VI., telling Noel to be on the look-out with his cinema at 8 A.M., when he expected to be at the foot of the final pyramid. This suggests that Mallory expected to make, with oxygen, very rapid progress. On the other hand, Geoffrey Bruce and Odell both reported that they obtained little or no benefit from its use. The first such occasion was up to 23,000 feet, where its use could scarcely be expected to produce dramatic results in acclimatised climbers. The second occasion was at 27,000 feet, when Odell discarded oxygen and felt better without it. With the deference due from one who was not actually present, I suggest that the fault may have rested with the apparatus, and that the improvement in Odell's condition may have been due to the discarding of useless weight and partly possibly to the euphoria usually associated with anoxæmia. We know that the apparatus was cumbersome; inefficient, and leaky. We do not know to what extent Irvine's improvements and corrections, carried out without proper equipment and under the most difficult of conditions, may have broken down in use. The appearance of Mallory and Irvine, still below the final pyramid at 12.50, four and a half hours late, may have been due to a breakdown of the apparatus.

If, then, the oxygen school believes in the usefulness of oxygen for high climbers, whether acclimatised or not, and the no-oxygen school believes in its usefulness for the unacclimatised, a method of attack in conformity with both points of view appears at first sight to be obvious. It should be possible to eliminate the necessity for acclimatisation by using oxygen from a low level on the mountain and climbing it at alpine speed. But here two great problems present themselves. It is very difficult to construct an apparatus which will without waste deliver the required quantity of oxygen while the climber is eating and sleeping; and it is impossible at the moment to find an apparatus which can be trusted never to go wrong. The failure of his oxygen apparatus near the top of Everest would mean death to the unacclimatised mountaineer.

The other extreme view has also been presented, but never by anyone with experience of Himalayan climbing-the view that Everest should be attacked by a party prepared, if necessary, to spend a year upon the mountain. To rush a mountain is folly, unsound in theory and disastrous in practice. Siege tactics have been proved sound. But there must be moderation even in slowness. The weather of the great peaks allows only a limited time in which to make the ascent, and many months upon a mountain undermine the health of the climbing party. It is possible that before sufficient acclimatisation for an oxygenless assault on the summit of Everest has been attained, altitude deterioration may have set in. If by relying on oxygen for the last few thousand feet of Everest it is possible to reduce the time on the mountain and thus the danger of deterioration, the chances of a successful attempt will be increased. Whether this can be done will be determined by direct experiment in a steel decompression chamber.

The practical difficulties of oxygen are serious. The apparatus in use in 1924 was so heavy that, in the opinion of some, its weight outbalanced its advantages. Valves tend to freeze or leak, and complicated taps are difficult to work under trying conditions. Many improvements have been made in the last five years, but there is room for more. There should be produced a light, simple, and efficient apparatus, thoroughly tested in refrigerators and mid-tunnels and on the mountains of Europe. This task has been undertaken by a committee of the British Association. If such an apparatus can be designed it should, as soon as permission can be obtained, be placed in the hands of a young, well-drilled, and well-organised party. Such a party will, in my opinion, climb Everest. It will at any rate show us whether or not oxygen can be of service to the unacclimatised man.

\section{The Principles of Evolution Revealed by Palæontology.*}

\section{By Prof. Henry Fatrfield Osborn, For.Mem.R.S.}

$I^{\mathrm{N}}$ honour of Darwin our first thought is that natural selection is the sole survivor of the age-long theories and hypotheses clustering about evolution. Selection alone has stood the test of survival of the fittest, yet we must severely limit the powers of selection as Darwin imagined them in his earlier and more sanguine frame of mind, and glean the elements of truth pervading all the other hypotheses and theories. It is a striking fact that the zoologists, experimentalists, and geneticists who, a quarter century ago, were stoutly combating Wallace, Weismann, and other super selectionists, have, one after another, returned to the Darwinian fold and are now almost unani* Paper read before Section D (Zoology) of the British Association,
following Prof. E. B. Poulton's presidential address, entitled "A Century of Evolution ", on Sept. 24. This is the sixth of a series of papers by the author on the origin of species. mously teaching their students, as if it were a demonstrated fact, that evolution progresses by the survival of fortuitously adaptive mutations.

To the mind of the palæontologist these teachings are pure Darwinism camouflaged in new language. Bateson, founder of the genetic school, was the only one to confess frankly his utter failure to explain the origin of species; few have displayed similar courage.

When we consider the youthful zoology and the infantile palæontology of Darwin's time (1809-82), our admiration for his genius and marvellous powers of generalisation constantly increases. What would his generalisations have risen to with our present knowledge? He foresaw the promised land of palæontology, but did not live to enter it. The ratio of the 8767 vertebrate species known in

No. 3239, Vol. 128] 